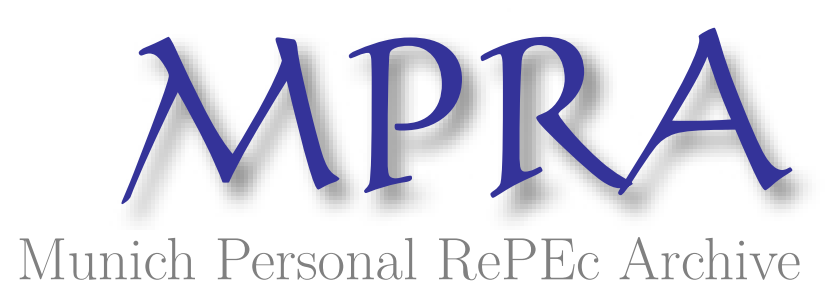

\title{
The welfare cost of one-size-fits-all patent protection
}

\author{
Chu, Angus C. \\ Institute of Economics, Academia Sinica
}

September 2009

Online at https://mpra.ub.uni-muenchen.de/23286/

MPRA Paper No. 23286, posted 14 Jun 2010 10:08 UTC 


\title{
The Welfare Cost of One-Size-Fits-All Patent Protection
}

\author{
Angus C. Chu ${ }^{\mathrm{a}, \mathrm{b}}$
}

June 2010

\begin{abstract}
To analyze the welfare gain from allowing for differentiated patent protection across sectors, this study develops a two-sector quality-ladder growth model in which patent breadth is a policy variable and derives optimal patent breadth under two patent regimes. We show that (a) uniform optimal patent breadth is a weighted average of sector-specific optimal patent breadth, and (b) sector-specific optimal patent breadth is larger in the sector that has a larger market size and more technological opportunities. To derive the optimal policy, we allow for an arbitrary path of patent breadth and derive the optimal path by solving a Stackelberg differential game. We find that the optimal path of patent breadth under each patent regime is stationary, timeconsistent and subgame perfect. Finally, we perform a numerical investigation and find that even a moderate degree of asymmetry across sectors can generate a significant welfare cost of uniform patent protection.
\end{abstract}

Keywords: economic growth, R\&D, uniform patent protection, time-consistent patent policy JEL classification: $\mathrm{O} 31, \mathrm{O} 34$

\footnotetext{
${ }^{a}$ School of Economics, Shanghai University of Finance and Economics, China. Email: angusccc@gmail.com. The author is very grateful to Been-Lon Chen, Guido Cozzi, Silvia Galli, Michel Juillard (the Editor), Yiting Li, Thomas Renstrom and especially two anonymous referees for their insightful comments and helpful suggestions. The usual disclaimer applies.

${ }^{\mathrm{b}}$ Institute of Economics, Academia Sinica, Taipei, Taiwan.
} 
"The economic evidence is overwhelming that innovation works differently in different industries, and that the way patents affect innovation also differs enormously by industry. The question for patent policy is how to respond to those differences."

- Burk and Lemley (2009, p. 4-5)

\section{Introduction}

An important shortcoming of the patent system is that diverse industries, such as biotechnology, software and semiconductors, are governed by the same set of rules. For example, as a result of the TRIPS agreement, ${ }^{1}$ the statutory term of patent in the US is 20 years for inventions across almost all fields of technology, and this one-size-fits-all patent policy is unlikely to provide the appropriate incentives for innovation in every industry. Fortunately, there are other patent-policy instruments that can be controlled by policymakers. An important example is patent breadth that determines the broadness or scope of a patent. When an inventor applies for a patent, she makes a number of claims about the invention in her application to be reviewed by a patent examiner. A flexible patent regime should allow the level of patent breadth to vary across industries.

In a recent book, Burk and Lemley (2009) also suggest that the courts should tailor the unitary patent rules through interpretations and applications to suit the different needs of diverse industries. ${ }^{2}$ As stated in the quote at the beginning of this paper, Burk and Lemley (2009) argue that the process of innovation varies substantially across industries and responds to patent policy in different ways. Therefore, the optimal design of a patent system should take into account these crucial differences. Applying the Burk-Lemley proposal to our analysis of patent breadth implies

\footnotetext{
${ }^{1}$ The World Trade Organization's Agreement on Trade-Related Aspects of Intellectual Property Rights (TRIPS), initiated in the 1986-94 Uruguay Round, establishes a minimum level of intellectual property protection that must be provided by all member countries.

${ }^{2}$ Burk and Lemley (2009) note that the courts already treat innovation across industries differently, but they also argue that the current degree of differentiation is insufficient.
} 
that the courts should be given the discretion to decide how broadly or narrowly patent claims are to be interpreted on a case-by-case basis tailoring to the needs of different industries. It is useful to note that while Burk and Lemley (2009) consider the effects of sector-specific patent protection on innovation, we analyze its implications on economic growth and social welfare. In our theoretical model, we find that under both sector-specific and uniform optimal patent breath, the aggregate growth rate of the economy is the same. However, the regime under sector-specific patent protection achieves the same rate of innovation with a more efficient allocation of $R \& D$ inputs and hence exhibits a higher level of social welfare.

In summary, in this study, we develop a two-sector quality-ladder growth model in which patent breadth is a policy variable and apply the model to analyze the welfare implications of sector-specific patent protection. We derive optimal patent breadth under two policy regimes (a) uniform patent breadth across sectors and (b) sector-specific patent breadth. Also, we perform a numerical investigation on the potential welfare gain from allowing for differentiated patent breadth across sectors.

Specifically, we extend the quality-ladder model of Grossman and Helpman (1991) by incorporating two sectors that are differentiated by market size and technological opportunity. Within this framework, we show that (a) sector-specific optimal patent breadth is larger in the sector that has a larger market size and more technological opportunities and (b) uniform optimal patent breadth is a weighted average of sector-specific optimal patent breadth and the optimal weight is given by each sector's market size. Comparing the differences in economic growth and social welfare under the two patent regimes, we find that although the growth-rate differential is zero in this model, the welfare difference is generally nonzero and determined by an interaction between technological opportunity and market size across sectors. This finding has an important 
policy implication that even if empirical studies do not find a significant improvement in growth upon implementing differentiated patent protection across sectors, the welfare gain can still be significant. In the numerical analysis, we find that even a moderate degree of asymmetry across sectors can generate a significant welfare gain from allowing for sector-specific patent breadth.

Some interesting recent studies, such as Acemoglu and Akcigit (2009) and Mosel (2009), also analyze the implications of differentiated patent protection across sectors. In addition to some modeling differences in the growth-theoretic framework, the present study differs from the above studies in the following ways. Firstly, these studies model patent protection as a constant parameter and numerically compute the parameter value that maximizes growth or welfare. In contrast, we allow for an arbitrary path of patent breadth and analytically derive the optimal path by solving a differential game, ${ }^{3}$ in which policymakers move first by choosing a time path of patent breadth and then households response by choosing a time path of consumption (i.e., a Stackelberg differential game). We find that the optimal path of patent breadth under each policy regime is stationary, time-consistent and subgame perfect. Time consistency and subgame perfectness imply that policymakers have no incentive to deviate from the optimal path of patent breadth under any realization of the state variables along and off the equilibrium path.

In their seminal study, Kydland and Prescott (1977) consider patent protection as an important example of time-inconsistent policies for which they point out the following problem. "Given that resources have been allocated to inventive activity which resulted in a new product or process, the efficient policy is not to permit patent protection." To show that optimal patent policy is not necessarily time inconsistent, this study adopts a differential-game approach and derives time-consistent optimal patent breadth in a modified version of the Grossman-Helpman

\footnotetext{
${ }^{3}$ A differential game is a dynamic game in which the state variables evolve according to differential equations. See, for example, Dockner et al. (2000) for a comprehensive textbook treatment on differential games.
} 
model, ${ }^{4}$ which is a workhorse model in the literature on R\&D-based growth. Time inconsistency does not arise in this model because the equilibrium allocation at any point in time depends only on the current level of patent breadth and is independent of future patent policies.

A second difference with Acemoglu and Akcigit (2009) is that while they consider the level of patent protection to be differentiated by the technological gap between the leader and the follower in an industry, we consider patent breadth to be differentiated by an industry's market size and technological opportunity that drive the observable industry differences in productivity growth and R\&D intensity according to Klenow (1996). In other words, we examine a different set of industry-specific characteristics that are also important features of the economy and hence complement the analysis in Acemoglu and Akcigit (2009), who also find a significant welfare gain from sector-specific patent protection. Thirdly, while Mosel (2009) considers a related set of industry-specific characteristics in a different model, he focuses on the interesting effects of sector-specific patent length on economic growth. Given that growth maximization does not necessarily give rise to welfare maximization, it is useful to consider the welfare effects as well, and the present study fills this gap in the literature.

The seminal study of the patent-design literature is Nordhaus (1969), who concludes that the optimal level of patent protection should tradeoff the static welfare costs of markup pricing against the dynamic welfare gains from innovation. A comprehensive review of the subsequent developments in this literature can be found in Scotchmer (2004). While most studies in the patent-design literature are based on a qualitative partial-equilibrium setting, the macroeconomic literature plays a complementary role in providing dynamic general-equilibrium (DGE) analysis on patent policy. For example, Iwaisako and Futagami (2003) and Futagami and Iwaisako (2007)

\footnotetext{
${ }^{4}$ It can be shown that optimal patent breadth is also time consistent in the original Grossman-Helpman model. A proof is available upon request from the author.
} 
derive optimal patent length in the Romer model and show that it can be finite. Li (2001) extends the Grossman-Helpman model to consider patent breadth and finds that it has a positive effect on R\&D and economic growth. As for quantitative DGE analysis, Kwan and Lai (2003) evaluate the quantitative implications of the effective lifetime of patent in the Romer model and find that extending the effective lifetime of patent would lead to a substantial increase in R\&D and social welfare. Chu (2009) builds on the quality-ladder model in O'Donoghue and Zweimuller (2004) to provide a quantitative analysis on the effects of blocking patents and finds that reducing the negative effect of blocking patents on $R \& D$ would lead to a significant welfare gain. All these studies are based on R\&D growth models that have only one R\&D sector. ${ }^{5}$ The present study complements them by analyzing the welfare implications of patent policy in a growth model that features multiple R\&D sectors.

The rest of this study is organized as follows. Section 2 presents the model. Section 3 defines the equilibrium and analyzes its dynamic properties. Section 4 derives optimal patent breadth under the two policy regimes. Section 5 provides a quantitative analysis on welfare. The final section concludes, and proofs are relegated to Appendix A.

\section{A two-sector quality-ladder growth model with patent breadth}

The quality-ladder model is based on Grossman and Helpman (1991). ${ }^{6}$ In the original GrossmanHelpman model, there is a representative household who consumes a continuum of differentiated intermediate goods, and the quality of these intermediate goods improves overtime as a result of profit-seeking R\&D activities. Both R\&D and the production of intermediate goods require labor

\footnotetext{
${ }^{5}$ O'Donoghue and Zweimuller (2004) also analyze the case of two R\&D sectors in one of their extensions. However, their focus is on the distortionary effect of patent polices on the allocation of R\&D across sectors. Therefore, they only consider exogenous changes in the uniform level of patent protection.

${ }^{6}$ See, also, Aghion and Howitt (1992) and Segerstrom et al. (1990) for the other pioneering studies on the qualityladder growth model.
} 
input that is supplied by the household. When incentives for R\&D increase, labor is reallocated from production to R\&D. Consequently, production of intermediate goods falls, but the rate of quality improvement (i.e., economic growth) increases.

To consider the effects of patent protection, we modify the Grossman-Helpman model by incorporating patent breadth as a policy variable into the model following the formulation in $\mathrm{Li}$ (2001). Also, we assume that there are two sectors that produce different types of intermediate goods. To analyze sector-specific patent breadth, the two sectors are differentiated by market size and technological opportunity. Klenow (1996) also considers a two-sector R\&D model (but based on the Romer model of variety expansion) with three industry-specific characteristics that are commonly discussed in the industrial-organization literature. He finds that market size and technological opportunity best explain empirical differences in R\&D intensity and productivity growth across industries. Our model also captures the third industry-specific characteristic (i.e., appropriablility) analyzed in Klenow (1996) by featuring different rates of creative destruction across sectors.

In the following model, patent breadth is allowed to be a time-varying (but deterministic) variable. In Section 3, we show that the optimal path of patent breadth under each policy regime is stationary, time-consistent and subgame perfect.

\subsection{Households}

There is a unit continuum of identical households, and their lifetime utility is given by

$$
U=\int_{0}^{\infty} e^{-\rho t} \ln C_{t} .
$$


$C_{t}$ denotes consumption at time $t$, and the parameter $\rho>0$ is the subjective discount rate. Households maximize utility subject to

$$
\dot{V}_{t}=R_{t} V_{t}+W_{t}-P_{t} C_{t} .
$$

$P_{t}$ denotes the price of consumption at time $t$. Each household supplies one unit of labor (chosen as the numeraire) to earn a wage income $W_{t}$ that will be normalized to unity. $V_{t}$ is the value of assets owned by households, and $R_{t}$ is the nominal rate of return. The familiar Euler equation is

$$
\dot{C}_{t} / C_{t}=r_{t}-\rho,
$$

where $r_{t} \equiv R_{t}-\dot{P}_{t} / P_{t}$ is the real interest rate.

\subsection{Consumption}

To consider a two-sector R\&D-based growth model, consumption is aggregated from two types of final goods $i \in\{1,2\}$. This aggregation process can be done by households themselves or by competitive firms, and these two formulations are equivalent to each other. We follow Klenow (1996) to consider a Cobb-Douglas aggregator given by

$$
C_{t}=\left(Y_{1, t}\right)^{\alpha}\left(Y_{2, t}\right)^{1-\alpha},
$$

where $\alpha \in(0,1)$ is the market-size parameter. We use this Cobb-Douglas aggregator instead of a CES aggregator because we want to allow $Y_{1, t}$ and $Y_{2, t}$ to grow at different rates. In the case of a CES aggregator, $Y_{1, t}$ and $Y_{2, t}$ growing at different rates is incompatible with a balanced-growth path. From standard cost minimization, the price index of consumption can be expressed as $P_{t}=\left(P_{1, t}\right)^{\alpha}\left(P_{2, t}\right)^{1-\alpha} /\left[\alpha^{\alpha}(1-\alpha)^{1-\alpha}\right]$, where $P_{1, t}$ and $P_{2, t}$ are the prices of $Y_{1, t}$ and $Y_{2, t}$ respectively.

The condition demand functions for $Y_{1, t}$ and $Y_{2, t}$ are respectively 


$$
\begin{gathered}
P_{1, t} Y_{1, t}=\alpha P_{t} C_{t}, \\
P_{2, t} Y_{2, t}=(1-\alpha) P_{t} C_{t} .
\end{gathered}
$$

Therefore, $\alpha$ determines the output share of the two types of final goods (i.e., the market size).

\subsection{Final goods}

Final goods $i \in\{1,2\}$ are produced by a standard Cobb-Douglas aggregator over a unit continuum of differentiated intermediate goods $X_{i, t}(j)$ indexed by $j \in[0,1]$.

$$
Y_{i, t}=\exp \left(\int_{0}^{1} \ln X_{i, t}(j) d j\right)
$$

This sector is perfectly competitive, and final-goods firms take both the output and input prices

as given. Given (7), the price index of final goods $i$ can be expressed as $P_{i, t}=\exp \left(\int_{0}^{1} \ln P_{i, t}(j) d j\right)$, where $P_{i, t}(j)$ is the price of $X_{i, t}(j)$.

\subsection{Intermediate goods}

In each sector $i \in\{1,2\}$, there is a unit continuum of differentiated intermediate goods indexed by $j \in[0,1]$. Each intermediate goods $j$ of sector $i$ is produced by a monopolistic leader, who holds a patent on the latest innovation. This industry leader dominates the market temporarily until the arrival of the next innovation. ${ }^{7}$ The production function for the leader of intermediate goods $j$ in sector $i$ is

$$
X_{i, t}(j)=z^{n_{i, t}(j)} L_{i, t}(j)
$$

\footnotetext{
${ }^{7}$ Grossman and Helpman (1991) show that the next innovation must come from a new entrant due to the Arrow replacement effect. Cozzi (2007) provides an alternative interpretation on the Arrow effect that the incumbents' choice of R\&D is indeterminate so that the aggregate economy behaves as if innovation is targeted only by entrants.
} 
$L_{i, t}(j)$ denotes the number of workers producing intermediate goods $j$ of sector $i . z>1$ is the exogenous step size of productivity improvement from each innovation. $n_{i, t}(j)$ is the number of innovations that have occurred in intermediate goods $j$ of sector $i$ as of time $t$. The marginal cost of production for the leader of intermediate goods $j$ in sector $i$ is

$$
M C_{i, t}(j)=W_{t} / z^{n_{i, t}(j)} .
$$

As commonly assumed in the literature, the current leader and the former leader engage in Bertrand competition. The profit-maximizing price for the current leader is a constant markup over the marginal cost.

$$
P_{i, t}(j)=\mu_{i, t}\left(W_{t} / z^{n_{i, t}(j)}\right)
$$

where $\mu_{i, t}=z^{b_{i, t}}$ and $b_{i, t} \in(0,1]$ is the level of patent breadth at time $t .{ }^{8}$ Grossman and Helpman (1991) assume complete patent protection against imitation (i.e., $b_{i, t}=1$ ). Li (2001) generalizes the patent regime to allow for incomplete patent protection. We follow Li's (2001) formulation of patent breadth here. Because of incomplete protection, the current leader's innovation enables the former leader to increase her productivity by a factor of $z^{1-b}$ without infringing the current leader's patent. Therefore, the limit-pricing markup for the current leader is $z^{b}$. A larger patent breadth enables the current leader to charge a higher markup, and the resulting increase in profit improves incentives for R\&D. ${ }^{9}$ For the rest of this study, we use $\mu_{i, t} \equiv \mu\left(z, b_{i, t}\right)$ to denote patent breadth for convenience and consider changes in $\mu_{i, t}$ coming from changes in $b_{i, t}$ only.

\footnotetext{
${ }^{8}$ When an inventor applies for a patent, she makes a number of claims about the invention to be patented. If these claims are narrowly interpreted, then competitors may be able to imitate around them to avoid infringement.

${ }^{9} \mathrm{Li}$ (2001) also generalizes (7) to a CES function. In this case, the markup is $\min \left\{z^{b}, \varepsilon /(\varepsilon-1)\right\}$, where $\varepsilon \in(1, \infty)$ is the elasticity of substitution between intermediate goods. Therefore, when $z^{b}<\varepsilon /(\varepsilon-1)$, the effect of patent breadth on R\&D and growth is the same as in the case of a Cobb-Douglas production function.
} 


\section{$2.5 R \& D$}

Denote the value of the latest innovation in intermediate goods $j$ of sector $i$ by $V_{i, t}(j) .{ }^{10}$ Due to the Cobb-Douglas specification in (7), the amount of profit is the same across industries within a sector (i.e., $\pi_{i, t}(j)=\pi_{i, t}$ for $\left.j \in[0,1]\right)$. As a result, $V_{i, t}(j)=V_{i, t}$ for $j \in[0,1]$ in a symmetric equilibrium in which the arrival rate of innovation is equal across industries within a sector. ${ }^{11}$ The familiar no-arbitrage condition for $V_{i, t}$ is

$$
R_{t} V_{i, t}=\pi_{i, t}+\dot{V}_{i, t}-\lambda_{i, t} V_{i, t}
$$

Intuitively, (11) equates the interest rate to the asset return per unit of asset. The asset return is the sum of (a) the profit $\pi_{i, t}$ generated by this asset, (b) the potential capital gain $\dot{V}_{i, t}$ and (c) the expected capital loss $\lambda_{i, t} V_{i, t}$ due to creative destruction for which $\lambda_{i, t}$ is the aggregate Poisson arrival rate of innovation in sector $i$.

There is a unit continuum of R\&D entrepreneurs in each sector $i$. They hire $\mathrm{R} \& \mathrm{D}$ workers $H_{i, t}$ for innovation, and the expected profit for R\&D in sector $i$ is

$$
\Pi_{i, t}=V_{i, t} \tilde{\lambda}_{i, t}-W_{t} H_{i, t}
$$

where $\tilde{\lambda}_{i, t}=\varphi_{i} H_{i, t}$ is the individual Poisson arrival rate of innovation. Following Klenow (1996), we allow the technological-opportunity parameter $\varphi_{i}$ to vary across sectors. ${ }^{12}$ Without loss of generality, we assume that $\varphi_{1} \leq \varphi_{2}$. The zero-expected-profit condition for R\&D in sector $i$ is

\footnotetext{
${ }^{10}$ It will become clear why we use $V_{i, t}$ to denote the market value of inventions and $V_{t}$ to denote the value of assets owned by households.

${ }^{11}$ We follow the standard approach in the literature to focus on the symmetric equilibrium. See, for example, Cozzi et al. (2007) for a theoretical justification for the symmetric equilibrium to be the unique rational-expectation equilibrium in the quality-ladder growth model.

${ }^{12}$ In the literature, the parameter $\varphi_{i}$ is sometimes referred to as R\&D efficiency. Because our study relates to Klenow (1996), we follow his terminology to refer to $\varphi_{i}$ as technological opportunity. Intuitively, in a sector that has more technological opportunities, the chance of discovering an invention is higher for a given amount of R\&D input.
} 


$$
\varphi_{i} V_{i, t}=W_{t}=1,{ }^{13}
$$

where the second equality of (13) follows from choosing labor as the numeraire.

The Cobb-Douglas specification in (7) implies that each intermediate goods $j$ of sector $i$ employs an equal number of production workers. Substituting (8) into (7) yields $Y_{i, t}=Z_{i, t} L_{i, t}$, where the level of technology in sector $i$ is defined as

$$
Z_{i, t} \equiv \exp \left(\int_{0}^{1} n_{i, t}(j) d j \ln z\right)=\exp \left(\int_{0}^{t} \lambda_{i, \tau} d \tau \ln z\right)
$$

The second equality of (14) is based on the law of large numbers, which implies that the average number of innovations across a continuum of industries equals its expected value. Differentiating the $\log$ of (14) with respect to time yields the growth rate of total factor productivity (TFP) in sector $i$ given by

$$
g_{i, t} \equiv \dot{Z}_{i, t} / Z_{i, t}=\lambda_{i, t} \ln z
$$

where $\lambda_{i, t}=\tilde{\lambda}_{i, t}=\varphi_{i} H_{i, t}$ in equilibrium.

\section{Decentralized equilibrium}

The equilibrium is a time path of allocations $\left\{C_{t}, Y_{i, t}, X_{i, t}(j), L_{i, t}, H_{i, t}\right\}_{t=0}^{\infty}$, a time path of prices $\left\{P_{t}, P_{i, t}, P_{i, t}(j), W_{t}, R_{t}, V_{t}, V_{i, t}\right\}_{t=0}^{\infty}$ and a time path of polices $\left\{\mu_{i, t}\right\}_{t=0}^{\infty}$. Also, at each instant of time,

(a) households choose $\left\{C_{t}\right\}$ to maximize utility taking $\left\{P_{t}, W_{t}, R_{t}\right\}$ as given;

(b) competitive firms produce $\left\{C_{t}\right\}$ using $\left\{Y_{i, t}\right\}$ as inputs to maximize profit taking $\left\{P_{t}, P_{i, t}\right\}$ as given;

\footnotetext{
${ }^{13}$ The sector with a larger $\varphi_{i}$ attracts more R\&D and hence has a higher rate of creative destruction that reduces $V_{i, t}$.
} 
(c) competitive firms in sector $i$ produce $\left\{Y_{i, t}\right\}$ using $\left\{X_{i, t}(j)\right\}$ as inputs to maximize profit taking $\left\{P_{i, t}, P_{i, t}(j)\right\}$ as given;

(d) the leader of intermediate goods $j$ of sector $i$ produces $\left\{X_{i, t}(j)\right\}$ and chooses $\left\{P_{i, t}(j)\right\}$ subject to Bertrand competition to maximize profit taking $\left\{W_{t}\right\}$ as given;

(e) competitive $\mathrm{R} \& \mathrm{D}$ entrepreneurs in sector $i$ choose $\left\{H_{i, t}\right\}$ to maximize expected profit taking $\left\{W_{t}, V_{i, t}\right\}$ as given;

(f) the labor market clears such that $L_{1, t}+L_{2, t}+H_{1, t}+H_{2, t}=1$;

(g) the market value of inventions adds up to the value of assets owned by households such that $V_{1, t}+V_{2, t}=V_{t}$.

\subsection{Balanced-growth path}

In this section, we firstly derive the equilibrium labor allocations for an arbitrary path of patent breadth $\left\{\mu_{1, t}, \mu_{2, t}\right\}_{t=0}^{\infty}$. Then, we show that given a stationary path of patent breadth $\left\{\mu_{1}, \mu_{2}\right\}_{t=0}^{\infty}$, the economy is always on a unique and stable balanced-growth path. ${ }^{14}$

Lemma 1: Given an arbitrary path of patent breadth $\left\{\mu_{1, t}, \mu_{2, t}\right\}_{t=0}^{\infty}$, the equilibrium labor allocations at time t are

$$
L_{1, t}=\alpha\left(1+\frac{\rho}{\varphi_{1}}+\frac{\rho}{\varphi_{2}}\right) \frac{1}{\mu_{1, t}}
$$

\footnotetext{
${ }^{14}$ As in Grossman and Helpman (1991), the implicit assumptions behind this result are (a) at any point in time, each industry has an existing leader with a competitor one step down the quality ladder and (b) R\&D entrepreneurs always implement their inventions immediately (i.e., ruling out endogenous implementation cycles).
} 


$$
\begin{gathered}
L_{2, t}=(1-\alpha)\left(1+\frac{\rho}{\varphi_{1}}+\frac{\rho}{\varphi_{2}}\right) \frac{1}{\mu_{2, t}}, \\
H_{1, t}=\alpha\left(1+\frac{\rho}{\varphi_{1}}+\frac{\rho}{\varphi_{2}}\right)\left(\frac{\mu_{1, t}-1}{\mu_{1, t}}\right)-\frac{\rho}{\varphi_{1}}, \\
H_{2, t}=(1-\alpha)\left(1+\frac{\rho}{\varphi_{1}}+\frac{\rho}{\varphi_{2}}\right)\left(\frac{\mu_{2, t}-1}{\mu_{2, t}}\right)-\frac{\rho}{\varphi_{2}} .
\end{gathered}
$$

The equilibrium labor allocations at time tonly depend on the level of patent breadth at time $t$.

Furthermore, given a stationary path of patent breadth $\left\{\mu_{1}, \mu_{2}\right\}_{t=0}^{\infty}$, the economy is always on a unique and stable balanced-growth path.

Proof: See Appendix A.

Equations (16) to (19) reveal an important property of the Grossman-Helpman model that the equilibrium labor allocations are independent of future patent policies. This property implies that an increase in patent breath $\mu_{i, t}$ at any time $t$ is accompanied by an increase in $\lambda_{i, t}=\varphi_{i} H_{i, t}$ in such a way that $V_{i, t}$ remains unchanged, ${ }^{15}$ and this useful property gives rise to time-consistent optimal patent policies. In the next section, we also show that the optimal path of patent breadth is stationary.

Given a stationary path of patent breadth, the economy is on a balanced-growth path, and the steady-state equilibrium allocations are quite intuitive. A larger $\alpha$ increases both $L_{1}$ and $H_{1}$. Intuitively, as the market size of final goods 1 increases, the economy devotes more labor to production and R\&D in sector 1 . A larger $\mu_{1}$ decreases $L_{1}$ and increases $H_{1}$. A larger patent breadth in sector 1 leads to a reallocation of labor from production to $R \& D$ within the sector.

\footnotetext{
${ }^{15}$ See the proof of Lemma 1.
} 
However, note that the sum of $L_{1}$ and $H_{1}$ is independent of $\mu_{1}$. In other words, a change in the relative level of patent breadth does not lead to a reallocation of labor across sectors. Similar to an increase in $\mu_{1}$, a larger $\varphi_{1}$ decreases $L_{1}$ and increases $H_{1}$. Interestingly, in this case, $L_{2}$ and $H_{2}$ also decrease. In other words, as the technological opportunity of sector 1 improves, the economy not only reallocates labor from production to R\&D within the sector but also across sectors. Finally, the consumption growth rate $g_{t} \equiv \dot{C}_{t} / C_{t}$ along the balanced-growth path is

$$
g=\alpha g_{1}+(1-\alpha) g_{2}=\left(\alpha \varphi_{1} H_{1}+(1-\alpha) \varphi_{2} H_{2}\right) \ln z
$$

\section{Optimal patent breadth}

The previous section shows that given a constant level of patent breadth, the economy is always on a balanced-growth path. This section shows that the optimal path of patent breadth under each policy regime is indeed stationary. We firstly derive sector-specific optimal patent breadth and then uniform optimal patent breadth. Finally, we derive the first-best allocation and compare it with the equilibrium allocations under the two patent regimes.

\subsection{Sector-specific optimal patent breadth}

This section derives the optimal path of sector-specific patent breadth denoted by $\left\{\mu_{1, t}^{*}, \mu_{2, t}^{*}\right\}_{t=0}^{\infty}$. Technically, we are solving a Stackelberg differential game, ${ }^{16}$ in which policymakers move first by choosing a time path of $\left\{\mu_{1, t}, \mu_{2, t}\right\}_{t=0}^{\infty}$ and then households respond by choosing a time path of consumption. It is well known that this Ramsey approach usually gives rise to time-inconsistent policies (i.e., after households make their best response, policymakers have incentives to deviate

\footnotetext{
${ }^{16}$ See, for example, Xie (1997) and Karp and Lee (2003) for a discussion.
} 
from their chosen policies ex post). Time inconsistency does not arise in this model because the equilibrium allocation at any time $t$ depends only on the current level of patent breadth and hence is independent of future patent policies. Therefore, policymakers have no incentive to manipulate future policies for the purposing of influencing current allocations.

Proposition 1: The optimal path of sector-specific patent breadth is stationary, time-consistent, subgame perfect and given by

$$
\begin{gathered}
\mu_{1, t}^{*}=\mu_{1}^{*}=\alpha\left(1+\frac{\rho}{\varphi_{1}}+\frac{\rho}{\varphi_{2}}\right) \frac{\varphi_{1} \ln z}{\rho}, \\
\mu_{2, t}^{*}=\mu_{2}^{*}=(1-\alpha)\left(1+\frac{\rho}{\varphi_{1}}+\frac{\rho}{\varphi_{2}}\right) \frac{\varphi_{2} \ln z}{\rho} .
\end{gathered}
$$

Proof: See Appendix A.

We impose a parameter restriction $\max \left\{\mu_{1}^{*}, \mu_{2}^{*}\right\} \leq z$ to ensure that the breadth parameter $b_{i}$ is between zero and one for $i \in\{1,2\}$. Equations (21) and (22) show that a larger discount rate reduces the optimal level of patent breadth in both sectors. This is because the benefit of a higher growth rate on households' welfare becomes smaller as $\rho$ increases. The quality step size $z$ has a positive externality effect on the growth rate as shown in (15); therefore, a larger $z$ increases optimal patent breadth in both sectors. An improvement in sector 1's technological opportunity $\varphi_{1}$ increases optimal patent breadth in sector 1 and decreases that of sector 2. Similarly, a larger $\alpha$ (i.e., sector 1's market size) increases optimal patent breadth in sector 1 and decreases that of sector 2 . 
To have a better understanding of these results, we express social welfare as a function of $\mu_{1}$ and $\mu_{2}$. Given the balanced-growth behavior of the model under a stationary path of patent breadth, households' lifetime utility in (1) can be re-expressed as

$$
U=\frac{1}{\rho}\left(\ln C_{0}+\frac{g}{\rho}\right)=\frac{1}{\rho}\left[\alpha\left(\ln L_{1}+\left(\frac{\varphi_{1} \ln z}{\rho}\right) H_{1}\right)+(1-\alpha)\left(\ln L_{2}+\left(\frac{\varphi_{2} \ln z}{\rho}\right) H_{2}\right)\right],
$$

where the second equality is obtained by dropping the exogenous terms $Z_{1,0}$ and $Z_{2,0}$. Inserting (16) - (19) into (1a) and then dropping the terms that are independent of $\mu_{1}$ and $\mu_{2}$ yield

$$
\widetilde{U}\left(\mu_{1}, \mu_{2}\right)=\frac{1}{\rho}\left[\alpha\left(-\ln \mu_{1}+\alpha \varphi_{1} \Gamma\left(\frac{\mu_{1}-1}{\mu_{1}}\right)\right)+(1-\alpha)\left(-\ln \mu_{2}+(1-\alpha) \varphi_{2} \Gamma\left(\frac{\mu_{2, t}-1}{\mu_{2, t}}\right)\right)\right]{ }^{17}
$$

where $\Gamma \equiv\left(\frac{\ln z}{\rho}\right)\left(1+\frac{\rho}{\varphi_{1}}+\frac{\rho}{\varphi_{2}}\right)$ is a composite parameter. Equation (1b) yields some interesting insights. On the one hand, an increase in $\mu_{1}$ has a negative effect on welfare by decreasing final goods produced in sector 1 , and this effect is captured by $-\ln \mu_{1}$. On the other hand, an increase in $\mu_{1}$ has a positive effect on welfare by increasing the growth rate of technology in sector 1 , and this effect is captured by $\alpha \varphi_{1} \Gamma\left(\mu_{1}-1\right) / \mu_{1}$. Therefore, the optimal $\mu_{1}^{*}$ simply balances between the social cost and the social benefit. The marginal benefit depends on $\alpha \varphi_{1} \Gamma$, which is increasing in $\alpha, \varphi_{1}$ and $z$ and decreasing in $\rho$ and $\varphi_{2}$. This reasoning explains the comparative statics of $\mu_{1}^{*}$. A similar reasoning also explains the comparative statics of $\mu_{2}^{*}$. Finally, substituting (21) and (22) into (16) - (19) yields

$$
L_{1}\left(\mu_{1}^{*}\right)=\frac{\rho}{\varphi_{1} \ln z}
$$

\footnotetext{
${ }^{17}$ Here we use $\widetilde{U}$ because some exogenous terms in $U$ have been dropped.
} 


$$
\begin{gathered}
L_{2}\left(\mu_{2}^{*}\right)=\frac{\rho}{\varphi_{2} \ln z}, \\
H_{1}\left(\mu_{1}^{*}\right)=\alpha\left(1+\frac{\rho}{\varphi_{1}}+\frac{\rho}{\varphi_{2}}\right)-\left(1+\frac{1}{\ln z}\right) \frac{\rho}{\varphi_{1}}, \\
H_{2}\left(\mu_{2}^{*}\right)=(1-\alpha)\left(1+\frac{\rho}{\varphi_{1}}+\frac{\rho}{\varphi_{2}}\right)-\left(1+\frac{1}{\ln z}\right) \frac{\rho}{\varphi_{2}} .
\end{gathered}
$$

We will compare (23) - (26) to the first-best labor allocations in Section 4.3.

\subsection{Uniform optimal patent breadth}

This section considers the policy regime under uniform patent breadth denoted by $\bar{\mu}_{t} \equiv \mu_{1, t}=\mu_{2, t}$ and derives the optimal path of uniform patent breadth $\left\{\bar{\mu}_{t}^{*}\right\}_{t=0}^{\infty}$. As before, we are solving a Stackelberg differential game, in which policymakers move first by choosing a time path of $\left\{\bar{\mu}_{t}\right\}_{t=0}^{\infty}$ and then households respond by choosing a time path of consumption.

Proposition 2: The optimal path of uniform patent breadth is stationary, time-consistent, subgame perfect and given by

$$
\bar{\mu}_{t}^{*}=\bar{\mu}^{*}=\alpha \mu_{1}^{*}+(1-\alpha) \mu_{2}^{*}=\left(\alpha^{2} \varphi_{1}+(1-\alpha)^{2} \varphi_{2}\right)\left(1+\frac{\rho}{\varphi_{1}}+\frac{\rho}{\varphi_{2}}\right) \frac{\ln z}{\rho} .
$$

Proof: See Appendix A.

Proposition 2 shows that uniform optimal patent breadth is a weighted average of sectorspecific optimal patent breadth, and the optimal weights are $\alpha$ and $1-\alpha$. The effects of $\rho$ and $z$ on optimal patent breadth are the same as before. As for an increase in $\alpha$, it has a positive 
(negative) effect on $\bar{\mu}^{*}$ if $\alpha \varphi_{1}$ is greater (less) than $(1-\alpha) \varphi_{2}$. Intuitively, a larger $\alpha$ increases optimal patent breadth of sector 1 and decreases that of sector 2 . Therefore, when the level of patent breadth is constrained to be the same across sectors, whether a larger $\alpha$ increases or decreases $\bar{\mu}^{*}$ depends on the relative magnitude of the above two forces. At a large (small) $\alpha$, the effect from sector 1 (sector 2) dominates, so that $\bar{\mu}^{*}$ is an U-shape function in $\alpha$. Similarly, $\varphi_{i}$ has an U-shape effect on $\bar{\mu}^{*}$, which is initially decreasing in $\varphi_{i}$ and subsequently increasing in $\varphi_{i}$, because a larger $\varphi_{i}$ also has opposing effects on optimal patent breadth in the two sectors.

To have a better understanding of these results, we express social welfare as a function of $\bar{\mu}$. For the case of uniform patent breadth $\bar{\mu},(1 \mathrm{~b})$ becomes

$$
\widetilde{U}(\bar{\mu})=\frac{1}{\rho}\left[-\ln \bar{\mu}+\left(\alpha^{2} \varphi_{1}+(1-\alpha)^{2} \varphi_{2}\right) \Gamma\left(\frac{\bar{\mu}-1}{\bar{\mu}}\right)\right] .
$$

where $\Gamma$ is defined as before. Equation (1c) yields the following insights. On the one hand, an increase in $\bar{\mu}$ has a negative effect on welfare by decreasing final goods produced in both sectors, and this effect is captured by $-\ln \bar{\mu}$. On the other hand, an increase in $\bar{\mu}$ has a positive effect on welfare by increasing the growth rate of technology in both sectors, and this effect is captured by $\left(\alpha^{2} \varphi_{1}+(1-\alpha)^{2} \varphi_{2}\right) \Gamma(\bar{\mu}-1) / \bar{\mu}$. Once again, the optimal $\bar{\mu}$ balances between the social cost and the social benefit. The marginal benefit depends on $\left(\alpha^{2} \varphi_{1}+(1-\alpha)^{2} \varphi_{2}\right) \Gamma$, which is increasing in $z$, decreasing in $\rho$, and non-monotonic in $\alpha, \varphi_{1}$ and $\varphi_{2}$. This explains the comparative statics of $\bar{\mu}^{*}$. Substituting (27) into (16) - (19) yields

$$
L_{1}\left(\bar{\mu}^{*}\right)=\frac{\alpha}{\alpha^{2} \varphi_{1}+(1-\alpha)^{2} \varphi_{2}}\left(\frac{\rho}{\ln z}\right)
$$




$$
\begin{gathered}
L_{2}\left(\bar{\mu}^{*}\right)=\frac{1-\alpha}{\alpha^{2} \varphi_{1}+(1-\alpha)^{2} \varphi_{2}}\left(\frac{\rho}{\ln z}\right), \\
H_{1}\left(\bar{\mu}^{*}\right)=\alpha\left(1+\frac{\rho}{\varphi_{1}}+\frac{\rho}{\varphi_{2}}\right)-\left(1+\frac{\alpha \varphi_{1}}{\alpha^{2} \varphi_{1}+(1-\alpha)^{2} \varphi_{2}} \frac{1}{\ln z}\right) \frac{\rho}{\varphi_{1}} \\
H_{2}\left(\bar{\mu}^{*}\right)=(1-\alpha)\left(1+\frac{\rho}{\varphi_{1}}+\frac{\rho}{\varphi_{2}}\right)-\left(1+\frac{(1-\alpha) \varphi_{2}}{\alpha^{2} \varphi_{1}+(1-\alpha)^{2} \varphi_{2}} \frac{1}{\ln z}\right) \frac{\rho}{\varphi_{2}} .
\end{gathered}
$$

We will also compare (28) - (31) to the first-best labor allocations in Section 4.3.

\subsection{First-best allocation}

In this section, we drive the first-best labor allocations by having the social planner chooses a time path of $\left\{L_{1, t}, L_{2, t}, H_{1, t}, H_{2, t}\right\}_{t=0}^{\infty}$ to maximize (1). The optimization yields a corner solution in which either $H_{1, t}$ or $H_{2, t}$ is equal to zero for all $t$ depending on whether $\alpha \varphi_{1}$ is greater or less than $(1-\alpha) \varphi_{2}$. For illustrative purposes, we consider $\alpha \varphi_{1}>(1-\alpha) \varphi_{2}$, so that $H_{2, t}=0$ for all $t$.

Lemma 2: The optimal path $\left\{L_{1, t}^{*}, L_{2, t}^{*}, H_{1, t}^{*}, H_{2, t}^{*}\right\}_{t=0}^{\infty}$ is stationary and given by

$$
\begin{gathered}
L_{1, t}^{*}=L_{1}^{*}=\frac{\rho}{\varphi_{1} \ln z}, \\
L_{2, t}^{*}=L_{2}^{*}=\left(\frac{1-\alpha}{\alpha}\right) \frac{\rho}{\varphi_{1} \ln z}, \\
H_{1, t}^{*}=H_{1}^{*}=1-\frac{\rho}{\alpha \varphi_{1} \ln z}, \\
H_{2, t}^{*}=H_{2}^{*}=0 .
\end{gathered}
$$

Proof: See Appendix A 
Comparing (23) - (26) and (32) - (35) shows that $L_{1}\left(\mu_{1}^{*}\right)=L_{1}^{*}$ and $L_{2}\left(\mu_{2}^{*}\right)>L_{2}^{*}$. In other words, compared to the first-best allocations, the equilibrium under $\left\{\mu_{1}^{*}, \mu_{2}^{*}\right\}$ devotes too much labor to production in sector 2 and too little labor to R\&D (i.e., $\left.H_{1}\left(\mu_{1}^{*}\right)+H_{2}\left(\mu_{2}^{*}\right)<H_{1}^{*}+H_{2}^{*}\right)$. Also, the first-best allocations (34) and (35) are efficient in terms of allocating R\&D labor to the sector that has a larger effect on welfare (recall that $\left.\alpha \varphi_{1}>(1-\alpha) \varphi_{2}\right)$. As for the allocation of R\&D labor under $\left\{\mu_{1}^{*}, \mu_{2}^{*}\right\}$, we see that $H_{1}\left(\mu_{1}^{*}\right)<H_{1}^{*}$ and $H_{2}\left(\mu_{2}^{*}\right)>H_{2}^{*}=0$. Therefore, the firstbest optimal growth rate is strictly higher than the equilibrium growth rate under sector-specific optimal patent breadth unless $\alpha \varphi_{1}=(1-\alpha) \varphi_{2}$, in which case the growth rates are equal.

Comparing (28) - (31) and (32) - (35) shows that $L_{1}\left(\bar{\mu}^{*}\right)>L_{1}^{*}$ and $L_{2}\left(\bar{\mu}^{*}\right)>L_{2}^{*}$. In other words, the equilibrium under uniform patent breadth allocates too much labor to production in both sectors and too little labor to R\&D (i.e., $\left.H_{1}\left(\bar{\mu}^{*}\right)+H_{2}\left(\bar{\mu}^{*}\right)<H_{1}^{*}+H_{2}^{*}\right)$. As for the allocation of R\&D labor, we see that $H_{1}\left(\bar{\mu}^{*}\right)<H_{1}^{*}$ and $H_{2}\left(\bar{\mu}^{*}\right)>H_{2}^{*}=0$. In this case, the first-best growth rate is also strictly higher than the equilibrium growth rate under uniform patent breadth unless $\alpha \varphi_{1}=(1-\alpha) \varphi_{2}$, in which case the growth rates are equal.

To have a better understanding of the above results, we follow Grossman and Helpman (1991) to compare the equilibrium allocation with the optimal allocation. To do this, we firstly rewrite the R\&D zero-expected-profit condition $V_{i} \lambda_{i}=W H_{i}$ as ${ }^{18}$

$$
\frac{H_{i}}{L_{i}}=\lambda_{i}\left(\frac{\mu_{i}-1}{\rho+\lambda_{i}}\right)
$$

\footnotetext{
${ }^{18}$ See the proof of Lemma 1 for derivations.
} 
for any arbitrary $\mu_{i}$. Equation (36) gives the ratio of equilibrium $R \& D$ and production labors in sector $i$ as a function of $\rho, \mu_{i}$ and $\lambda_{i}=\varphi_{i} H_{i}$. We can also express the ratio of optimal R\&D and production labors as

$$
\frac{H_{1}^{*}}{L_{1}^{*}}=\lambda_{1}^{*}\left(\frac{\ln z}{\rho}\right),
$$

and $H_{2}^{*} / L_{2}^{*}=0$ because $\alpha \varphi_{1}>(1-\alpha) \varphi_{2}$. Comparing $H_{1} / L_{1}$ and $H_{1}^{*} / L_{1}^{*}$ yields the following insights. First, $\ln z / \rho$ in (37) captures the consumer-surplus and intertemporal-spillover effects discussed in Grossman and Helpman (1991). These effects are positive externalities meaning that the larger are the effects, the more likely that $H_{1} / L_{1}<H_{1}^{*} / L_{1}^{*}$. Second, $\left(\mu_{1}-1\right) /\left(\rho+\lambda_{1}\right)$ in (36) captures the business-stealing effect that is a negative externality. Thus, whether $H_{1}^{*} / L_{1}^{*}$ is below or above $H_{1} / L_{1}$ depends on the relative magnitude of these three externalities that are the same as the ones in the Grossman-Helpman model. What is different in this two-sector model is that $H_{2} / L_{2}>H_{2}^{*} / L_{2}^{*}$ because $H_{2}^{*}=0$ given that $\alpha \varphi_{1}>(1-\alpha) \varphi_{2}$. In other words, there is always an overinvestment in $R \& D$ in sector 2 . As a result of the externalities, the decentralized equilibrium deviates from the optimal allocation. Therefore, patent policy serves as a partial remedy for this market failure. However, even with sector-specific patent breadth, there are only two policy instruments, and hence, they are insufficient to eliminate all the distortion wedges in $L_{1}, L_{2}, H_{1}$ and $\mathrm{H}_{2}$.

\section{Growth and welfare effects of sector-specific patent protection}

In this section, we consider the growth and welfare differences between the two patent regimes. The results can be summarized as follows. We find that the growth difference is zero. However, 
the welfare difference depends on an interaction between $\alpha$ and $\varphi_{1} / \varphi_{2}$, and the welfare cost of uniform patent protection is generally non-negligible.

\subsection{Growth difference between the two patent regimes}

To compare the difference in growth across regimes, we firstly substitute (25) and (26) into (20) to derive the equilibrium growth rate under sector-specific optimal patent breadth $g\left(\mu_{1}^{*}, \mu_{2}^{*}\right)$ and substitute (30) and (31) into (20) to derive the equilibrium growth rate under uniform optimal patent breadth $g\left(\bar{\mu}^{*}\right)$. In both cases, we find that the equilibrium growth rate is

$$
g\left(\mu_{1}^{*}, \mu_{2}^{*}\right)=g\left(\bar{\mu}^{*}\right)=\left(\alpha^{2} \varphi_{1}+(1-\alpha)^{2} \varphi_{2}\right)\left(1+\frac{\rho}{\varphi_{1}}+\frac{\rho}{\varphi_{2}}\right) \ln z-\rho(1+\ln z) .
$$

Therefore, the growth difference between sector-specific and uniform optimal patent breadth is zero in this model.

To have a better understanding of the result that the two regimes yield the same growth rate, we substitute (18) and (19) into (20) to derive

$$
g=\left[\alpha^{2} \varphi_{1}\left(\frac{\mu_{1}-1}{\mu_{1}}\right)+(1-\alpha)^{2} \varphi_{2}\left(\frac{\mu_{2}-1}{\mu_{2}}\right)\right]\left(1+\frac{\rho}{\varphi_{1}}+\frac{\rho}{\varphi_{2}}\right) \ln z-\rho \ln z
$$

for any arbitrary $\mu_{1}$ and $\mu_{2}$. Equation (39) shows that the two patent regimes yield the same growth rate if and only if

$$
\alpha^{2} \varphi_{1}\left(\frac{\mu_{1}-1}{\mu_{1}}\right)+(1-\alpha)^{2} \varphi_{2}\left(\frac{\mu_{2}-1}{\mu_{2}}\right)=\alpha^{2} \varphi_{1}\left(\frac{\bar{\mu}-1}{\bar{\mu}}\right)+(1-\alpha)^{2} \varphi_{2}\left(\frac{\bar{\mu}-1}{\bar{\mu}}\right) .
$$

From Proposition 2, we know that uniform optimal patent breadth is a weighted average of sector-specific optimal patent breadth. Substituting $\bar{\mu}=\alpha \mu_{1}+(1-\alpha) \mu_{2}$ into (40) and applying a few steps of mathematical manipulation yield 


$$
\frac{\mu_{1}}{\mu_{2}}=\left(\frac{\alpha}{1-\alpha}\right) \frac{\varphi_{1}}{\varphi_{2}} .
$$

Comparing (21) and (22) shows that (41) is satisfied under sector-specific optimal patent breadth. This analysis enables us to highlight the key equations that give rise to the finding of zero growth difference. The first important equation is $g=\alpha g_{1}+(1-\alpha) g_{2}$, and this expression is a result of the Cobb-Douglas specification in (4). Secondly, the growth rate of technology in sector $i$ is $g_{i}=\left(\varphi_{i} \ln z\right) H_{i}$, which has constant returns to scale in R\&D labor. Consequently, $H_{i}$ has a closed-form solution given by (18) and (19). Furthermore, the assumption of log utility implies that households' lifetime utility in (1) can be expressed as $\rho U=\ln C_{0}+g / \rho$. Given this welfare function, optimal patent breadth under the two patent regimes satisfies $\bar{\mu}=\alpha \mu_{1}+(1-\alpha) \mu_{2}$ and (41). In other words, the finding that the two regimes yield the same growth rate is a modelspecific result based on a number of functional-form assumptions. Although many of the functional forms that we use are standard in the literature, we do not want to claim that this result is realistic. Nonetheless, this hypothetical result is a useful finding when it is considered along with our next result of a potentially sizable welfare gain. These two results together imply that even if empirical studies do not find any improvement in innovation upon implementing sectorspecific patent protection, the welfare gain can still be significant because the benefit of sectorspecific patent protection can be reflected in social welfare but not in economic growth.

\subsection{Welfare difference between the two patent regimes}

Despite the finding of zero growth difference between sector-specific and uniform patent breadth, the following results show that the welfare difference is generally non-negligible. Intuitively, uniform patent breadth achieves the same growth rate as sector-specific patent breadth but with a 
less efficient allocation of R\&D labor (i.e., $\left.H_{1}\left(\mu_{1}^{*}\right)+H_{2}\left(\mu_{2}^{*}\right)<H_{1}\left(\bar{\mu}^{*}\right)+H_{2}\left(\bar{\mu}^{*}\right)\right) .{ }^{19}$ Therefore, under uniform patent breadth, there is less labor available for production resulting into lower levels of consumption and welfare relative to the equilibrium under sector-specific patent breadth.

Given (1a) as a measure of welfare, we substitute (23) - (26) into (1a) to compute social welfare under sector-specific optimal patent breadth denoted by $U\left(\mu_{1}^{*}, \mu_{2}^{*}\right)$ and substitute (28) (31) into (1a) to compute social welfare under uniform optimal patent breadth denoted by $U\left(\bar{\mu}^{*}\right)$.

Proposition 3: The welfare difference $\Delta U \equiv U\left(\mu_{1}^{*}, \mu_{2}^{*}\right)-U\left(\bar{\mu}^{*}\right)$ can be expressed as

$$
\Delta U=\frac{1}{\rho}\left[\ln \left(\alpha^{2} \frac{\varphi_{1}}{\varphi_{2}}+(1-\alpha)^{2}\right)-\left(\alpha \ln \left(\alpha \frac{\varphi_{1}}{\varphi_{2}}\right)+(1-\alpha) \ln (1-\alpha)\right)\right] \geq 0
$$

which becomes a strict inequality if $\alpha \varphi_{1} \neq(1-\alpha) \varphi_{2}$.

Proof: See Appendix A.

Given that $\rho \Delta U$ depends on only two parameters $\alpha \in(0,1)$ and $\varphi_{1} / \varphi_{2} \in(0,1]$, we can numerically evaluate (42) to examine the properties of $\rho \Delta U$ without loss of generality. Figure 1 plots the welfare difference against $\alpha \in(0,1)$ and $\varphi_{1} / \varphi_{2} \in[0.2,1] \cdot{ }^{20}$ For the ease of interpretation, the welfare difference is re-expressed as $\delta$ denoting the equivalent variation in consumption per year defined as $U\left[C_{0}\left(\mu_{1}^{*}, \mu_{2}^{*}\right), g\left(\mu_{1}^{*}, \mu_{2}^{*}\right)\right]=U\left[(1+\delta) C_{0}\left(\bar{\mu}^{*}\right), g\left(\bar{\mu}^{*}\right)\right]$.

\section{[Insert Figure 1 here]}

\footnotetext{
${ }^{19}$ This inequality can be shown by using (25), (26), (30), (31) and a few steps of mathematical manipulation.

${ }^{20}$ The welfare difference can be very large when $\varphi_{1} / \varphi_{2} \in(0,0.2)$; thus, we report the results for $\varphi_{1} / \varphi_{2} \in[0.2,1]$ only. However, the properties of $\rho \Delta U$ are the same as in the rest of the parameter space.
} 
Figure 1 shows that for a given $\varphi_{1} / \varphi_{2}$, the welfare difference $\delta$ is an M-shape function in $\alpha$. Suppose we consider $\varphi_{1} / \varphi_{2}=1$. In this case, the two sectors are symmetric when $\alpha=0.5$. Under symmetry, the welfare loss from imposing uniform patent breadth is zero. As $\alpha$ deviates from 0.5 in either direction, the welfare loss becomes positive. This explains the U-shape pattern around 0.5 for $\varphi_{1} / \varphi_{2}=1$. As $\alpha \rightarrow 1$, the model becomes a one-sector model in which only sector 1 matters. In this case, $\bar{\mu}^{*} \rightarrow \mu_{1}^{*}$; therefore, the welfare loss $\delta$ approaches zero. The same is true for $\alpha \rightarrow 0$. This explains the M-shape pattern of $\delta$ for $\varphi_{1} / \varphi_{2}=1$. As $\varphi_{1} / \varphi_{2}$ decreases, optimal patent breadth of sector 2 increases while that of sector 1 decreases. Thus, households benefit from differentiated patent breadth even when $\alpha=0.5$. When $\varphi_{1} / \varphi_{2}<1$, uniform patent breadth is optimal only if $\alpha$ increases above 0.5 to diminish the importance of sector 2 . This explains why the interior minimum of $\delta$ in Figure 1 shifts towards larger $\alpha$ as $\varphi_{1} / \varphi_{2}$ decreases.

Next we consider the welfare difference with respect to changes in $\varphi_{1} / \varphi_{2}$ for a given $\alpha$. When $\alpha \leq 0.5$, the welfare loss $\delta$ is always decreasing in $\varphi_{1} / \varphi_{2}$. Intuitively, when $\alpha \leq 0.5$, optimal patent breadth of sector 1 is smaller than that of sector 2 (i.e., $\mu_{1}^{*}<\mu_{2}^{*}$ ), but this gap shrinks as $\varphi_{1} / \varphi_{2}$ increases. Consequently, the welfare loss $\delta$ from imposing uniform patent breadth diminishes as $\varphi_{1} / \varphi_{2}$ increases when $\alpha \leq 0.5$. However, when $\alpha \in(0.5,1)$, the welfare loss $\delta$ can be non-monotonic in $\varphi_{1} / \varphi_{2}$. When $\alpha \in(0.5,1), \mu_{1}^{*}<\mu_{2}^{*}$ only if $\varphi_{1} / \varphi_{2}$ is sufficiently small, in which case, a larger $\varphi_{1} / \varphi_{2}$ continues to reduce the gap between $\mu_{1}^{*}$ and $\mu_{2}^{*}$ giving rise to a smaller welfare loss $\delta$. However, if $\varphi_{1} / \varphi_{2}$ becomes sufficiently large, then $\mu_{1}^{*}>\mu_{2}^{*}$. In this case, any further increase in $\varphi_{1} / \varphi_{2}$ widens the gap between $\mu_{1}^{*}$ and $\mu_{2}^{*}$ giving rise to a larger welfare loss $\delta$. In other words, whenever $\alpha$ is sufficiently large (small) such that $\mu_{1}^{*}$ is above 
(below) $\mu_{2}^{*}$ for a given $\varphi_{1} / \varphi_{2}$, an increase (a decrease) in $\varphi_{1} / \varphi_{2}$ would widen the gap between $\mu_{1}^{*}$ and $\mu_{2}^{*}$ resulting into a larger welfare loss $\delta$.

Having understood the qualitative pattern of $\delta$ that depends on a nontrivial interaction between $\alpha$ and $\varphi_{1} / \varphi_{2}$, we now consider the magnitude of the welfare loss. Figure 1 shows that the welfare loss ranges from zero to as large as $50 \%$ of consumption per year. To focus on the effect of asymmetry in technological opportunity across sectors, Table 1 summarizes the welfare costs of uniform patent protection for $\alpha=0.5$ from Figure 1.

\begin{tabular}{|c|c|c|c|c|c|c|c|c|c|}
\hline \multicolumn{7}{|c|}{ Table 1: Welfare costs of uniform patent breadth for $\boldsymbol{\alpha}=\mathbf{0 . 5}$} \\
\hline$\varphi 1 / \varphi 2$ & 0.20 & 0.30 & 0.40 & 0.50 & 0.60 & 0.70 & 0.80 & 0.90 & 1.00 \\
\hline$\delta$ & $34.2 \%$ & $18.7 \%$ & $10.7 \%$ & $6.1 \%$ & $3.3 \%$ & $1.6 \%$ & $0.6 \%$ & $0.1 \%$ & $0.0 \%$ \\
\hline
\end{tabular}

The policy implication from this illustrative numerical exercise is that even a moderate degree of asymmetry in technological opportunity across sectors can generate a non-negligible welfare cost of one-size-fits-all patent policy. Also, empirical evidence suggests that $\varphi_{i}$ varies significantly across sectors. For example, Klenow (1996) finds that although R\&D intensity and TFP growth at the industry level are positively correlated, R\&D can only explain a small fraction of the variation in industry-level TFP growth implying that technological opportunities differ significantly across industries. Furthermore, (14) implies that the log level of TFP in sector $i$ can be expressed as $\ln Z_{i, t}=\left(\varphi_{i} \ln z\right) S_{i, t}$, where $S_{i, t} \equiv \int_{0}^{t} H_{i, \tau} d \tau$ denotes the stock of R\&D in sector $i$. Some empirical studies, such as Verspagen (1995), Los and Verspagen (2000) and Cameron (2000), have estimated the effects of R\&D stock on the level of TFP/output at the industry level, and they find that the effects of R\&D stock vary substantially across industries. 


\section{Conclusion}

In this study, we have developed a two-sector R\&D-based growth model and applied the growththeoretic framework to analyze the welfare implications of sector-specific patent protection. In summary, we find that sector-specific optimal patent breadth is larger in the sector that has a larger market size and more technological opportunities. If policymakers are constrained to implement uniform patent breadth, then they should set the uniform patent breadth to a weighted average of sector-specific optimal patent breadth. To derive the optimal path of patent breadth, we solve a Stackelberg differential game to show that optimal patent policy is not necessarily time inconsistent. Moreover, we find that the welfare gain from sector-specific patent protection can be substantial. Therefore, policymakers should take into consideration the heterogeneity across industries when designing the optimal system of patent protection. Also, this implication provides another reason as to why the harmonization of global patent protection may not be optimal given that the industrial structure differs significantly across some countries. ${ }^{21}$ As for the issue of scale effects, it is set aside by normalizing the supply of labor to unity so that it is the share of labor devoted to R\&D that determines growth as in the second-generation R\&D-based growth model. $^{22}$

Finally, we provide some caveats on the finding of a potentially sizable welfare gain from sector-specific patent protection. First, our analysis is based on the assumption that policymakers are well-informed about the different characteristics across industries. In reality, it could be quite costly to acquire this kind of information. Therefore, for real-world policy applications, the welfare gain from industry-specific patent protection should be evaluated in conjunction with the information-acquisition costs, and the magnitude of these costs remains as an empirical question.

\footnotetext{
${ }^{21}$ See, for example, Grossman and Lai (2004) for an interesting analysis on the welfare implications of harmonizing patent protection across countries.

${ }^{22}$ See Jones (1999) for an excellent discussion on scale effects in R\&D-based growth models.
} 
A second caveat is that if the patent authority has the ability to differentiate the level of patent protection across industries, then special interest groups would have incentives to lobby the government for special treatments in favor of their industries at the expense of consumers and other industries. ${ }^{23}$ Angell (2005) argues that this kind of lobbying activities is at work in the pharmaceutical industry. ${ }^{24}$ This problem is especially serious when special interest groups are the ones who provide industry-specific information to policymakers because any misinformation could result in a serious distortion of resource allocations.

\section{References}

Acemoglu, D., and Akcigit, U., 2009. State-dependent intellectual property rights policy. manuscript.

Aghion, P., and Howitt, P., 1992. A model of growth through creative destruction. Econometrica $60,323-351$.

Angell, M., 2005. The Truth About the Drug Companies: How They Deceive Us and What to Do About it. New York: Random House.

Burk, D., and Lemley, M., 2009. The Patent Crisis and How the Courts Can Solve It. The University of Chicago Press.

Cameron, G., 2000. R\&D and growth at the industry level. manuscript.

Chu, A., 2008. Special interest politics and intellectual property rights: an economic analysis of strengthening patent protection in the pharmaceutical industry. Economics \& Politics 20, $185-215$.

\footnotetext{
${ }^{23}$ The author would like to thank an anonymous referee for this insight.

${ }^{24}$ See Grossman and Helpman (2001) for a comprehensive analysis on special interest politics. Chu (2008) applies some of their tools to analyze pharmaceutical lobbying in the protection of intellectual property rights within an R\&D-based growth model and finds different welfare implications in a closed economy and in an open economy.
} 
Chu, A., 2009. Effects of blocking patents on R\&D: a quantitative DGE analysis. Journal of Economic Growth 14, 55-78.

Cozzi, G., 2007. The Arrow effect under competitive R\&D. B.E. Journal of Macroeconomics (Contributions) 7, article 2.

Cozzi, G., Giordani, P., and Zamparelli, L., 2007. The refoundation of the symmetric equilibrium in Schumpeterian growth models. Journal of Economic Theory 136, 788-797.

Dockner, E., Jorgensen, S., Long, N., and Sorger, G., 2000. Differential Games in Economics and Management Science. Cambridge University Press.

Futagami, K., and Iwaisako, T., 2007. Dynamic analysis of patent policy in an endogenous growth model. Journal of Economic Theory 132, 306-334.

Grossman, G., and Helpman, E., 1991. Quality ladders in the theory of growth. Review of Economic Studies 58, 43-61.

Grossman, G., and Helpman, E., 2001. Special Interest Politics. The MIT Press.

Grossman, G., and Lai, E., 2004. International protection of intellectual property. American Economic Review 94, 1635-1653.

Iwaisako, T., and Futagami, K., 2003. Patent policy in an endogenous growth model. Journal of Economics 78, 239-258.

Jones, C., 1999. Growth: with or without scale effects. American Economic Review 89, 139-144.

Karp, L., and Lee, I., 2003. Time-consistent policies. Journal of Economic Theory 112, 353-364.

Klenow, P., 1996. Industry innovation: where and why. Carnegie-Rochester Conference Series on Public Policy 44, 125-150.

Kwan, Y., and Lai, E., 2003. Intellectual property rights protection and endogenous economic growth. Journal of Economic Dynamics and Control 27, 853-873. 
Kydland, F., and Prescott, E., 1977. Rules rather than discretion: the inconsistency of optimal Plans. Journal of Political Economy 85, 473-492.

Li, C.-W., 2001. On the policy implications of endogenous technological progress. Economic Journal 111, C164-C179.

Los, B., and Verspagen, B., 2000. R\&D spillovers and productivity: evidence from U.S. manufacturing microdata. Empirical Economics 25, 127-148.

Mosel, M. 2009. Competition, imitation, and R\&D productivity in a growth model with sectorspecific patent protection. BGPE Discussion Paper No. 84.

Nordhaus, W., 1969. Invention, Growth, and Welfare. The MIT Press.

O’Donoghue, T., and Zweimuller, J., 2004. Patents in a model of endogenous growth. Journal of Economic Growth 9, 81-123.

Scotchmer, S., 2004. Innovation and Incentives. The MIT Press.

Segerstrom, P., Anant, T., and Dinopoulos, E., 1990. A Schumpeterian model of the product life cycle. American Economic Review 80, 1077-1092.

Verspagen, B., 1995. R\&D and productivity: a broad cross-section cross-country look. Journal of Productivity Analysis 6, 117-135.

Xie, D., 1997. On time inconsistency: a technical issue in Stackelberg differential games. Journal of Economic Theory 76, 412-430. 


\section{Appendix A}

Proof of Lemma 1: Households' current-value Hamiltonian is

$$
\Omega_{t}=\ln C_{t}+\omega_{t}\left(R_{t} V_{t}+W_{t}-P_{t} C_{t}\right) .
$$

The first-order conditions are

$$
\begin{gathered}
\frac{\partial \Omega_{t}}{\partial C_{t}}=\frac{1}{C_{t}}-\omega_{t} P_{t}=0, \\
\frac{\partial \Omega_{t}}{\partial V_{t}}=\omega_{t} R_{t}=\omega_{t} \rho-\dot{\omega}_{t}, \\
\frac{\partial \Omega_{t}}{\partial \omega_{t}}=R_{t} V_{t}+W_{t}-P_{t} C_{t}=\dot{V}_{t} .
\end{gathered}
$$

The transversality condition is $\lim _{t \rightarrow \infty} e^{-\rho t} \omega_{t} V_{t}=0$. Combining (A3) and (A4) yields

$$
\dot{\omega}_{t} V_{t}+\omega_{t} \dot{V}_{t}=\omega_{t} V_{t} \rho+\omega_{t} W_{t}-\omega_{t} P_{t} C_{t}
$$

Given households' first-order conditions, we use the market equilibrium conditions to solve (A5).

From (13), $W_{t}=\varphi_{1} V_{1, t}=\varphi_{2} V_{2, t}$. Combining this condition with $V_{1, t}+V_{2, t}=V_{t}$ yields

$$
V_{t}=\left(\frac{1}{\varphi_{1}}+\frac{1}{\varphi_{2}}\right) W_{t} .
$$

Substituting (A2) and (A6) into (A5) yields

$$
\dot{\omega}_{t} V_{t}+\omega_{t} \dot{V}_{t}=\omega_{t} V_{t}\left(\rho+\frac{\varphi_{1} \varphi_{2}}{\varphi_{1}+\varphi_{2}}\right)-1
$$

(A7) is a one-dimensional differential equation in $\omega_{t} V_{t}$, and the dynamic system is characterized by saddle-point stability. Therefore, $\omega_{t} V_{t}$ must jump to its unique steady state; otherwise, the transversality condition would be violated. To see this result, integrating (A7) with respect to time yields 


$$
\omega_{t} V_{t}=e^{\rho t} \beta+\left(\rho+\frac{\varphi_{1} \varphi_{2}}{\varphi_{1}+\varphi_{2}}\right)^{-1}
$$

where $\beta$ is an integration constant. The transversality condition implies that $\beta=0$. Therefore, $\omega_{t} V_{t}=\left(\rho+\frac{\varphi_{1} \varphi_{2}}{\varphi_{1}+\varphi_{2}}\right)^{-1}$ for all $t$. Substituting (A6) and $W_{t}=1$ into this condition yields

$$
\omega_{t}=\left(1+\frac{\rho}{\varphi_{1}}+\frac{\rho}{\varphi_{2}}\right)^{-1}
$$

for all $t$. Because $\omega_{t}$ is stationary, (A3) implies that $R_{t}=\rho$ for all $t$. Also, (A2) implies that

$$
P_{t} C_{t}=\left(1+\frac{\rho}{\varphi_{1}}+\frac{\rho}{\varphi_{2}}\right)
$$

In other words, nominal expenditure on consumption and the nominal interest rate are constant regardless of whether the path of patent breadth $\left\{\mu_{1, t}, \mu_{2, t}\right\}_{t=0}^{\infty}$ is stationary or not.

The rest of this proof derives the equilibrium labor allocations for an arbitrary path of patent breadth. From (5), (6) and (10), the factor payments to production workers in the two sectors are respectively

$$
\begin{gathered}
W_{t} L_{1, t}=P_{1, t} Y_{1, t} / \mu_{1, t}=\alpha P_{t} C_{t} / \mu_{1, t}, \\
W_{t} L_{2, t}=P_{2, t} Y_{2, t} / \mu_{2, t}=(1-\alpha) P_{t} C_{t} / \mu_{2, t} .
\end{gathered}
$$

Combining (A11) and (A12) yields

$$
\frac{L_{1, t}}{L_{2, t}}=\frac{\mu_{2, t}}{\mu_{1, t}}\left(\frac{\alpha}{1-\alpha}\right)
$$

The monopolistic profits in the two sectors are respectively

$$
\pi_{1, t}=\left(\frac{\mu_{1, t}-1}{\mu_{1, t}}\right) P_{1, t} Y_{1, t}=\left(\frac{\mu_{1, t}-1}{\mu_{1, t}}\right) \alpha P_{t} C_{t},
$$




$$
\pi_{2, t}=\left(\frac{\mu_{2, t}-1}{\mu_{2, t}}\right) P_{1, t} Y_{1, t}=\left(\frac{\mu_{2, t}-1}{\mu_{2, t}}\right)(1-\alpha) P_{t} C_{t} .
$$

(13) implies that $\dot{V}_{i, t}=0$. Imposing $\dot{V}_{i, t}=0$ on (11) yields

$$
\pi_{i, t}=\left(\rho+\lambda_{i, t}\right) V_{i, t},
$$

where we have applied the previously derived result ( $R_{t}=\rho$ for all $t$ ). Substituting (A11), (A14) and (A16) into (13) yields

$$
H_{1, t}=\left(\mu_{1, t}-1\right) L_{1, t}-\rho / \varphi_{1}
$$

Similarly, substituting (A12), (A15) and (A16) into (13) yields

$$
H_{2, t}=\left(\mu_{2, t}-1\right) L_{2, t}-\rho / \varphi_{2} .
$$

To close the model, we use the labor-market clearing condition given by

$$
L_{1, t}+L_{2, t}+H_{1, t}+H_{2, t}=1 \text {. }
$$

Solving the four equations (A13), (A17) - (A19) yields (16) - (19)

Proof of Proposition 1: In general, the households' Hamiltonian co-state variable $\omega_{t}$ should be treated as a state variable in the policymakers' dynamic optimization problem. However, (A9) shows that $\omega_{t}$ is constant; therefore, we can directly substitute (4) and $Y_{i, t}=Z_{i, t} L_{i, t}$ for $i \in\{1,2\}$ into (1) to derive the policymakers' current-value Hamiltonian given by

$$
\Phi_{t}\left(\mu_{1, t}, \mu_{2, t}\right)=\ln C_{t}+\phi_{1, t} \dot{Z}_{1, t}+\phi_{2, t} \dot{Z}_{2, t}
$$

where $\ln C_{t}=\alpha\left[\ln Z_{1, t}+\ln L_{1, t}\left(\mu_{1, t}\right)\right]+(1-\alpha)\left[\ln Z_{2, t}+\ln L_{2, t}\left(\mu_{2, t}\right)\right], \dot{Z}_{1, t}=Z_{1, t}\left(\varphi_{1} \ln z\right) H_{1, t}\left(\mu_{1, t}\right)$ and $\dot{Z}_{2, t}=Z_{2, t}\left(\varphi_{2} \ln z\right) H_{2, t}\left(\mu_{2, t}\right)$. The labor allocations $L_{1, t}\left(\mu_{1, t}\right), L_{2, t}\left(\mu_{2, t}\right), H_{1, t}\left(\mu_{1, t}\right)$ and $H_{2, t}\left(\mu_{2, t}\right)$ are given by (16) - (19). The first-order conditions are 


$$
\begin{gathered}
\frac{\partial \Phi_{t}}{\partial \mu_{1, t}}=-\frac{\alpha}{\mu_{1, t}}+\phi_{1, t} Z_{1, t}\left(\varphi_{1} \ln z\right)\left(1+\frac{\rho}{\varphi_{1}}+\frac{\rho}{\varphi_{2}}\right) \frac{\alpha}{\left(\mu_{1, t}\right)^{2}}=0, \\
\frac{\partial \Phi_{t}}{\partial \mu_{2, t}}=-\frac{1-\alpha}{\mu_{2, t}}+\phi_{2, t} Z_{2, t}\left(\varphi_{2} \ln z\right)\left(1+\frac{\rho}{\varphi_{1}}+\frac{\rho}{\varphi_{2}}\right) \frac{1-\alpha}{\left(\mu_{2, t}\right)^{2}}=0, \\
\frac{\partial \Phi_{t}}{\partial Z_{1, t}}=\frac{\alpha}{Z_{1, t}}+\phi_{1, t} \frac{\dot{Z}_{1, t}}{Z_{1, t}}=\phi_{1, t} \rho-\dot{\phi}_{1, t}, \\
\frac{\partial \Phi_{t}}{\partial Z_{2, t}}=\frac{1-\alpha}{Z_{2, t}}+\phi_{2, t} \frac{\dot{Z}_{2, t}}{Z_{2, t}}=\phi_{2, t} \rho-\dot{\phi}_{2, t} .
\end{gathered}
$$

Manipulating (A23) yields $\dot{\phi}_{1, t} Z_{1, t}+\phi_{1, t} \dot{Z}_{1, t}=\phi_{1, t} Z_{1, t} \rho-\alpha$. As before, this differential equation is characterized by saddle-point stability, so that $\phi_{1, t} Z_{1, t}$ must jump to its unique steady-state value given by

$$
\phi_{1, t} Z_{1, t}=\alpha / \rho
$$

for all $t$. Substituting (A25) into (A21) yields

$$
\mu_{1, t}=\alpha\left(1+\frac{\rho}{\varphi_{1}}+\frac{\rho}{\varphi_{2}}\right) \frac{\varphi_{1} \ln z}{\rho}
$$

for all $t$. Manipulating (A24) yields $\dot{\phi}_{2, t} Z_{2, t}+\phi_{2, t} \dot{Z}_{2, t}=\phi_{2, t} Z_{2, t} \rho-(1-\alpha)$, and this differential equation is also characterized by saddle-point stability. Therefore, $\phi_{2, t} Z_{2, t}$ must also jump to its unique steady-state value given by

$$
\phi_{2, t} Z_{2, t}=(1-\alpha) / \rho
$$

for all $t$. Substituting (A27) into (A22) yields

$$
\mu_{2, t}=(1-\alpha)\left(1+\frac{\rho}{\varphi_{1}}+\frac{\rho}{\varphi_{2}}\right) \frac{\varphi_{2} \ln z}{\rho}
$$


for all t. (A26) and (A28) show that the optimal path of sector-specific patent breadth is stationary. Given that the equilibrium labor allocations (16) - (19) are independent of future policies, the policymakers have no incentive to deviate from their chosen path of patent breadth at any point in time along the equilibrium path (i.e., time consistency). Furthermore, given that (A26) and (A28) are stationary and independent of the state variables, they are optimal under any realization of the state variables along and off the equilibrium path (i.e., subgame perfectness).

Proof of Proposition 2: The policymakers' current-value Hamiltonian in the case of uniform patent breadth is

$$
\Phi_{t}\left(\bar{\mu}_{t}\right)=\ln C_{t}+\phi_{1, t} \dot{Z}_{1, t}+\phi_{2, t} \dot{Z}_{2, t}
$$

where $\dot{Z}_{1, t}, \dot{Z}_{2, t}$ and $\ln C_{t}$ can be re-expressed as in Proposition 1. The labor allocations $L_{1, t}\left(\bar{\mu}_{t}\right)$, $L_{2, t}\left(\bar{\mu}_{t}\right), H_{1, t}\left(\bar{\mu}_{t}\right)$ and $H_{2, t}\left(\bar{\mu}_{t}\right)$ are given by $(16)-(19)$ as before. The first-order conditions are

$$
\frac{\partial \Phi_{t}}{\partial \bar{\mu}_{t}}=-\frac{1}{\bar{\mu}_{t}}+\phi_{1, t} Z_{1, t}\left(\varphi_{1} \ln z\right)\left(1+\frac{\rho}{\varphi_{1}}+\frac{\rho}{\varphi_{2}}\right) \frac{\alpha}{\left(\bar{\mu}_{t}\right)^{2}}+\phi_{2, t} Z_{2, t}\left(\varphi_{2} \ln z\right)\left(1+\frac{\rho}{\varphi_{1}}+\frac{\rho}{\varphi_{2}}\right) \frac{1-\alpha}{\left(\bar{\mu}_{t}\right)^{2}}=0
$$

$$
\begin{gathered}
\frac{\partial \Phi_{t}}{\partial Z_{1, t}}=\frac{\alpha}{Z_{1, t}}+\phi_{1, t} \frac{\dot{Z}_{1, t}}{Z_{1, t}}=\phi_{1, t} \rho-\dot{\phi}_{1, t}, \\
\frac{\partial \Phi_{t}}{\partial Z_{2, t}}=\frac{1-\alpha}{Z_{2, t}}+\phi_{2, t} \frac{\dot{Z}_{2, t}}{Z_{2, t}}=\phi_{2, t} \rho-\dot{\phi}_{2, t} .
\end{gathered}
$$

Manipulating (A31) and (A32) yields (A25) and (A27). Substituting them into (A30) yields

$$
\bar{\mu}_{t}=\alpha^{2}\left(1+\frac{\rho}{\varphi_{1}}+\frac{\rho}{\varphi_{2}}\right) \frac{\varphi_{1} \ln z}{\rho}+(1-\alpha)^{2}\left(1+\frac{\rho}{\varphi_{1}}+\frac{\rho}{\varphi_{2}}\right) \frac{\varphi_{2} \ln z}{\rho}
$$

for all $t$. (A33) shows that the optimal path of uniform patent breadth is stationary. (A33) is timeconsistent and subgame perfect for the same reasons as in Proposition 1. 
Proof of Lemma 2: The social planner's current-value Hamiltonian is

$$
\begin{aligned}
\Psi_{t}= & \alpha \ln Z_{1, t}+\alpha \ln L_{1, t}+(1-\alpha) \ln Z_{2, t}+(1-\alpha) \ln L_{2, t} \\
& +\psi_{1, t} Z_{1, t}\left(\varphi_{1} \ln z\right) H_{1, t}+\psi_{2, t} Z_{2, t}\left(\varphi_{2} \ln z\right) H_{2, t}+\psi_{3, t}\left(1-L_{1, t}-L_{2, t}-H_{1, t}-H_{2, t}\right)
\end{aligned} .
$$

The first-order conditions are

$$
\begin{gathered}
\frac{\partial \Psi_{t}}{\partial L_{1, t}}=\frac{\alpha}{L_{1, t}}-\psi_{3, t}=0, \\
\frac{\partial \Psi_{t}}{\partial L_{2, t}}=\frac{1-\alpha}{L_{2, t}}-\psi_{3, t}=0,
\end{gathered}
$$

$$
\frac{\partial \Psi_{t}}{\partial H_{1, t}}=\psi_{1, t} Z_{1, t}\left(\varphi_{1} \ln z\right)-\psi_{3, t} \leq 0
$$

$$
\frac{\partial \Psi_{t}}{\partial H_{2, t}}=\psi_{2, t} Z_{2, t}\left(\varphi_{2} \ln z\right)-\psi_{3, t} \leq 0,
$$

$$
\frac{\partial \Psi_{t}}{\partial Z_{1, t}}=\frac{\alpha}{Z_{1, t}}+\psi_{1, t} \frac{\dot{Z}_{1, t}}{Z_{1, t}}=\psi_{1, t} \rho-\dot{\psi}_{1, t},
$$

$$
\frac{\partial \Psi_{t}}{\partial Z_{2, t}}=\frac{1-\alpha}{Z_{2, t}}+\psi_{2, t} \frac{\dot{Z}_{2, t}}{Z_{2, t}}=\psi_{2, t} \rho-\dot{\psi}_{2, t}
$$

As before, integrating (A39) and (A40) with respect to time and setting the integration constants to zero as implied by the transversality conditions yields $\psi_{1, t} Z_{1, t}=\alpha / \rho$ and $\psi_{2, t} Z_{2, t}=(1-\alpha) / \rho$.

Substituting these conditions into (A37) and (A38) yields

$$
\psi_{3, t}=\frac{\alpha \varphi_{1} \ln z}{\rho}>\frac{(1-\alpha) \varphi_{2} \ln z}{\rho},
$$

which follows from $\alpha \varphi_{1}>(1-\alpha) \varphi_{2}$. Substituting (A41) into (A35) and (A36) yields (32) and (33). Combining (32), (33), $H_{2, t}=0$ from (A38) and $L_{1, t}+L_{2, t}+H_{1, t}+H_{2, t}=1$ yields (34). 
Proof of Proposition 3: We already know from (38) that the growth difference is zero across the two regimes. Therefore, the welfare difference is given by the difference in initial consumption.

(A42) $\Delta U=\frac{\ln C_{0}\left(\mu_{1}^{*}, \mu_{2}^{*}\right)-\ln C_{0}\left(\bar{\mu}^{*}\right)}{\rho}=\frac{\alpha \ln \left[L_{1}\left(\mu_{1}^{*}, \mu_{2}^{*}\right) / L_{1}\left(\bar{\mu}^{*}\right)\right]+(1-\alpha) \ln \left[L_{2}\left(\mu_{1}^{*}, \mu_{2}^{*}\right) / L_{2}\left(\bar{\mu}^{*}\right)\right]}{\rho}$.

Substituting (23), (24), (28) and (29) into (A42) yields

$$
\Delta U=\frac{1}{\rho}\left[\alpha \ln \left(\frac{\alpha^{2} \varphi_{1}+(1-\alpha)^{2} \varphi_{2}}{\alpha \varphi_{1}}\right)+(1-\alpha) \ln \left(\frac{\alpha^{2} \varphi_{1}+(1-\alpha)^{2} \varphi_{2}}{(1-\alpha) \varphi_{2}}\right)\right]
$$

Applying a few steps of mathematical manipulation to (A43) yields

$$
\Delta U=\frac{1}{\rho}\left[\ln \left(\alpha^{2} \frac{\varphi_{1}}{\varphi_{2}}+(1-\alpha)^{2}\right)-\left(\alpha \ln \left(\alpha \frac{\varphi_{1}}{\varphi_{2}}\right)+(1-\alpha) \ln (1-\alpha)\right)\right] .
$$

Finally, given that $\ln ($.$) is a concave function, Jensen's inequality implies that (A44) is weakly$ positive, and a strict inequality emerges if $\alpha \varphi_{1} \neq(1-\alpha) \varphi_{2}$. 
Figure 1: Welfare differences between sector-specific and uniform patent breadth

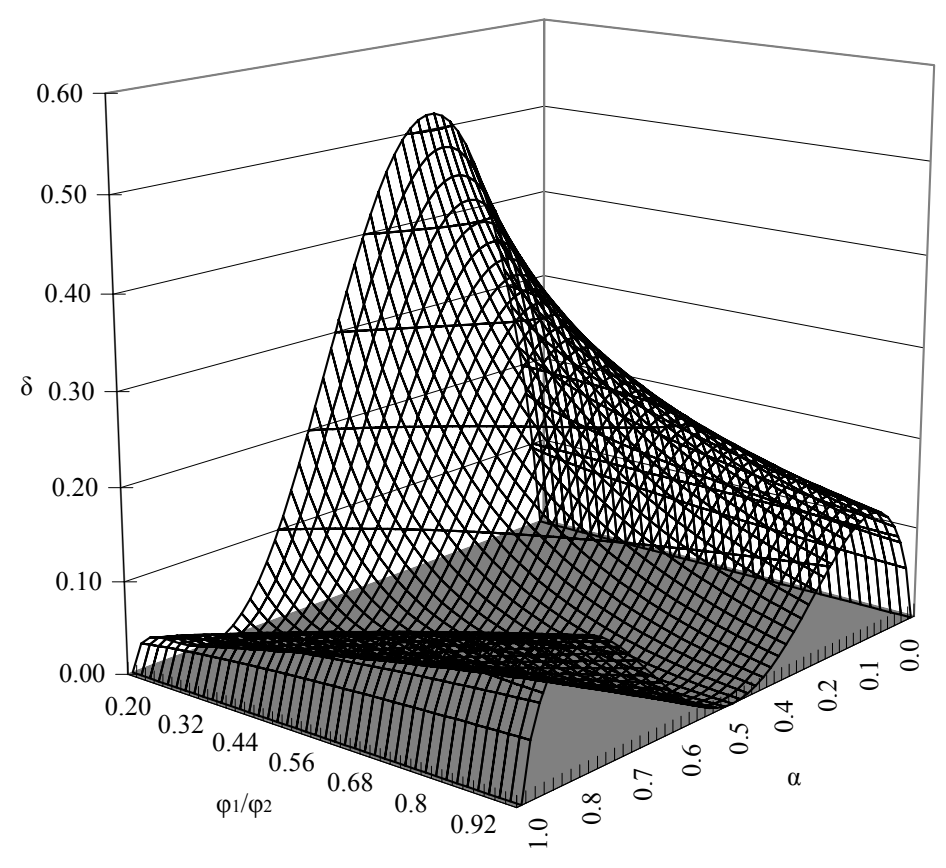

